\title{
Greek Nurses Attitudes towards Death
}

\author{
Malliarou Maria (Corresponding author)
}

Captain RN, MSc, PhDc, Scientific collaborator Technological Institution of Larisa

Nursing Department, Larisa, Greece

Tel: 30-241-085-1742Ｅ-mail: mmalliarou@gmail.com

\section{Sarafis Pavlos}

Lieutenant RN, Hel. Navy, Athens Naval \& Veterans Hospital

MSc Health services management H.O.U, MSc Public Health N.S.P.H- Hygienist

$\mathrm{PhD}$-scholar of the Onassis Foundation, Specialty in Infections \& Tropical Diseases, Athens, Greece

Tel: 30-210-726-1116_E-mail: psarafis@med.uoa.gr, psarafis@gmail.com

$$
\text { Sotiriadou Kiriaki }
$$

Captain RN, MSc, PhDc

E-mail:ksotiradou@gmail.com

Serafeim Tatiana

Major, RN, 424 General Military Hospital

Thessaloniki, Greece

Karathanasi Kostantinia

Major RN, MSc, 404 General Military Hospital

Larisa, Greece

E-mail: kkarathanasi@gmail.com

$$
\begin{aligned}
& \text { Moustaka Eleni } \\
& \text { Major RN, MSc }
\end{aligned}
$$

Theodosopoulou Eleni

Associate Professor, Nursing Faculty, National

Capodistrian University of Athens, Greece

Received: October 8, 2010 Accepted: October 26, 2010 doi:10.5539/gjhs.v3n1p224

\begin{abstract}
Introduction: Several studies explore the attitudes of nurses caring for dying patients but this is the first one exploring Greek nurses' attitude toward death.

Purpose/Objectives: To assess how Greek nurses feel about death and examine any relationships between their attitudes and demographic factors.

Design: Descriptive quantitative. The sample comprised of 150 hospital nurses (response rate 64\%).
\end{abstract}


Method: Voluntary and anonymous completion of the Death Attitude Profile-Revised (DAP-R), and a demographic questionnaire. The Death Attitude Profile-Revised (DAP-R) (Wong, Reker, \& Gesser, 1994) is a 32-item scale that uses a seven-point Likert scale to measure respondents' attitudes toward death. Demographic data, including gender, age, previous experience working with terminally ill patients, work setting (inpatient versus outpatient), years practising as an $\mathrm{RN}$ were collected. No identifying information was collected from the participants, ensuring the results were anonymous.

Results: $82 \%$ of respondents were female with a mean age of 35.54 years (19 min 48 max). The mean nursing experience was 12.1 years. Average scores on the DAP-R sub-scales ranged from 2.90 (escape sub-scale) to 5.63 (neutral sub-scale). Statistically significant relationships were noted among gender, and scores on the DAP-R. Nursing experience and age were the variables most likely to predict nurses' attitudes toward death. Nurses with specific education on palliative care had less difficulty talking about death and dying. The existence of Hospital-based teams (known as palliative care teams, supportive care teams, or symptom assessment teams) had statistically significant relationship with fear of death and neutral acceptance scores

Conclusions: In Greek hospitals nurses with more work experience tended to have more positive attitudes toward death and caring for dying patients.

Keywords: Death, Attitude, Nurse, Profile

\section{Introduction}

Death is an integral part of human existence; consequently it is inevitable that it is a subject of anguish and concern at some stage in our lives. "Death anxiety (thanatophobia) is defined as a feeling of dread, apprehension or solicitude (anxiety) when one thinks of the process of dying, or ceasing to be or what happens after death. Death is defined as the state of non-being, the termination of biological life." [Bond CW., 1998] Freud suggests that it is quite impossible for us to imagine what it is like to be dead [Freud S., 1915]. He argues that whenever we try to do this 'we survive as spectators' because deep down everyone thinks they are immortal. There are many factors influencing attitudes towards death, including personal experiences, culture, religion, age. Over the last century, death occurs mostly into institutions, rather than at homes.

Death is a natural occurrence in the health care setting. "The days when medical care was a small private matter between patient and general practitioner are long gone and will never return."[Fein Rashi, 1999] At the individual, organizational, and community level, cultivating responsibility and establishing accountability for the quality of care for patients approaching death are especially important tasks. Clinical nurses often care for patients in all stages of disease, from diagnosis to death or survivorship. A nurse's case load in a shift can consist of patients in varying phases of illness, presenting a challenge to nurses who must constantly adjust to the different needs of each patient and their families. Since nurses play a vital role in providing direct patient care, a patient's death may bring a sense of loss and grief which could eventually affect the way health care services are appropriately and adequately provided to other patients.

\section{Literature Review}

Several studies explore the attitudes of nurses caring for dying patients. Research shows that nurses have difficulty dealing with death [Brockopp DY, 1991; Payne SA, 1998; Servaty HL, 1996; Waltman N, 1992]. Many nurses struggle with negative personal issues concerning death and dying and therefore are uncomfortable providing care at the end of life. Schools of nursing do not educate nursing students sufficiently enough to care for patients at the end of life. "This lack of education has been reflected in the level and quality of end-of-life care provided to patients"[Mallory J., 2003].

Hopkinson (2005) developed a theory for caring for dying patients and proposed interventions for coping support, defending that if this aspect is not considered, it consequently may cause burnout in nurses who eventually leave the profession.

Rooda $e t a l$. found that nurses with a greater fear of death exhibited fewer positive attitudes toward caring for dying patients, whereas nurses who viewed death as a passageway to a happy afterlife demonstrated a more positive attitude in their care [Rooda LA, 1999]. The authors concluded that contact with terminally ill patients was shown to be a strong predictor of nurses' attitudes [Rooda LA, 1999]. Dunn et al., who conducted research in an oncology setting indicated that nurses with greater exposure to dying patients reported more positive attitudes [Dunn KS, 2005]. The fear of death could be reduced by improving interpersonal communication with all patients [Kübler-Ross E, 1969]. 


\section{Purpose of study}

To assess how Greek nurses feel about death and examine any relationships between their attitudes and demographic factors.

\section{Methodology}

\subsection{Study design}

The present study used a descriptive, quantitative design using a self-administered questionnaire.

\subsection{Sampling procedures}

A total of 150 Greek Nurses working in General Hospitals of Thessaly that provide Palliative care participated in the study voluntarily and anonymously. No peer counsellors to provide support to their colleagues exist in those hospitals. Data were collected from September 2009 to December 2009. The principal investigator (PI) or co-PI gave a brief introduction regarding the aim of the study, gave the necessary explanations and left the instrument packets in a general location for interested participants to pick up. Completed surveys were placed in a labelled box. The response rate was $64 \%$. Completion of the instruments took approximately 10-15 minutes, and no compensation was provided to the participants.

\subsection{The questionnaire}

In the first part of the questionnaire demographic data, including gender, age, previous experience working with terminally ill patients, work setting (inpatient versus outpatient), years practising, and years employed at the health facility were collected. The second part was comprised with The Death Attitude Profile-Revised (DAP-R) scale in order to measure respondents' attitudes toward death.

The Death Attitude Profile Revised (DAP-R) [Wong T.P., 1987; Wong T.P., 1994; Tomer Adrian, 2000] is a 32 -item scale that uses a seven-point Likert scale to measure respondents' attitudes toward death. The scale is comprised of five sub-scales to determine respondents' feelings of (a) fear of death, (b) death avoidance, (c) neutral acceptance, (d) approach acceptance, (e) escape acceptance. Fear of death describes negative thoughts and feelings about death (7 items consisting of 1, 2, 7, 18, 20,21, and 32). Death avoidance describes avoidance of thoughts of death as much as possible (5 items consisting of 3,10,12, 19, and 26). Neutral acceptance describes death is neither welcomed nor feared (5 items consisting of 6, 14, 24, 17 and 30). Approach acceptance describes death is viewed as a passageway to happy afterlife (10 items consisting of $4,8,13,15,16,22,25,27$, 28 , and 31 ). Escape acceptance describes death is viewed as an escape from a painful existence (5 items consisting of 5, 9, 11,23, and 29).

Each of the five sub-scale scores is calculated by adding together the respondent's scores on each of the items on that sub-scale and then dividing the sum by the number of items in that sub-scale. Thus, scores on each sub-scale can range between 1 and 7 . The mean sub-scale score is computed by adding the scores on each of the individual sub-scales, from one (strongly agree) to seven (strongly disagree) and then dividing by the number of items included in that sub-scale. A higher score indicates a stronger tendency to identify with that particular sub-scale.

\subsection{Data analysis processes}

Responses were examined to determine whether there were any associations among DAP-R scores and demographic data such as gender, age, educational level, previous experience working with terminally ill patients, work setting (inpatient versus outpatient), years practising as an RN, current contact with terminally ill patients. No identifying information was collected from the participants, ensuring the results were anonymous. Descriptive statistics were used to analyse the demographic data. SPSS ${ }$ version 17.0 has been used for the statistical analysis.

\subsection{Ethical issues}

The Ethics Committee of the Hospitals approved the study. All participants gave informed consent and they completed the questionnaire

\subsection{Limitations of the study}

One limitation has to do with the extent to which the findings can be generalized beyond the cases studied.

\section{Results}

\subsection{Demographic factors}

Females accounted for $82 \%$ of the sample. The mean age of the participants was 35.54 years $(S D=7.24)$, and the mean number of years of nursing experience was $12.1(S D=8.07)$. Education level of the sample was as follows: 
$42 \%$ were nurse aides with a two year nursing diploma, $42 \%$ had graduated technological nursing institutions and $16 \%$ had a university degree (Table 1 ).

\section{[Table 1-2]}

Of the respondents $48 \%$ stated that they think about dying patients at home and $20 \%$ confirmed that dealing with dying patients affect their personal life a lot.

\section{Statistical analysis}

\subsection{Distribution of data}

The Kolmogorov-Smirnov test was used to assess the distribution of the Greek DAP-R scores. Internal consistency reliability was determined by the calculation of Cronbach's $\alpha$ coefficient. Convergence validity was tested through inter-correlations (Pearson's $r$ ) among the sub-scales belonging to the questionnaire. The interval measurements were normally distributed, and therefore several parametric tests were employed to analyse the data. The significance level was set at $\mathrm{p}<0.05$.

The questionnaire sought information about socio-demographic characteristics and perception of death. Cronbach's $\alpha$ for the DAP-R score was 0.79 , indicating a high degree of internal consistency and homogeneity between the DAP-R items. The test-retest correlation coefficient for DAP-R scores was 0.791 indicating good stability. The Greek translation of the DAP-R demonstrated acceptable validity and reliability[Malliarou M, 2010].

Correlating Death Attitude Profile-Revised dimensions with other variables, some significant associations were found. As shown in Table 3, mean scores on the DAP-R subscales ranged from 2.90 for 'escape acceptance' to 5.63 for 'neutral acceptance'.

\section{[Table 3]}

The cross-correlation of the DAP-R sub-scales is given in Table 4. There is a positive relation between the 'fear of death' dimension and 'death avoidance', 'approach acceptance' and 'escape acceptance'. On the contrary, there is a negative relation between the 'fear of death' dimension and 'neutral acceptance'. Additionally, there is a positive relation between 'death avoidance' and 'approach acceptance', as well as between 'escape acceptance' and 'approach acceptance'.

\section{[Table 4]}

A considerably low positive relation between 'death avoidance' dimension and the age of respondents was also found. Therefore as the age of participants' increases, death avoidance increases as well. There has not been found a significant cross-correlation of age with other factors (Table 5).

\section{[Table 5]}

With increasing age, participants were more likely to avoid thoughts about death and were less likely to consider death as an integral part of life itself. Fear of death, approach acceptance and death avoidance were found to be related with gender. Men give higher scores in "fear of death" sub-scale than women $(p=0.047)$. Approach acceptance is higher in men than women and that is statistically significant with a $p=0.004$. Death avoidance correlates significantly with gender with a $\mathrm{p}=0.007$ (Table 6).

\section{[Table 6]}

Respondents with different years of employment as a nurse scored significantly differently on the DAP-R subscales. Pearson correlation analysis showed that there is a positive correlation between respondents' years of working experience and death avoidance $(\mathrm{r}=0.408, \mathrm{p}=0.000)$. Distribution of nurses' answers on each question of the DAP-R scale is shown in Table 7.

\section{[Table 7]}

\section{Discussion}

Studies of death attitudes have been conducted largely with samples of college students or healthcare professionals. It has been shown in other healthcare settings that providing care for dying patients can be an emotionally and physically taxing experience [McWhan K., 1991]. Attitudes on death can influence healthcare professionals' attitudes toward patients, willingness to talk about death and dying, and even medical decision making, as well as their choice to avoid or seek specialization in death exposure fields [Neimeyer, 1995; Neimeyer, 2004; Schulz, 1978]. As Neimeyer and Van Brunt ${ }^{[18]}$ note, attitudes on death leave unanswered the more critical question of how such personal concerns might influence their professional behavior. One factor that might mediate the relationship between experience with death and death attitudes is the type of relationship an individual has with a patient. 
The findings of the present study suggest that among the Greek nurses the more experienced cultivate better communication patterns and create better relationships with patients, so they view death from a neutral or more positive perspective than the less experienced. It seems that the more experienced nurses have developed strategies to cope with their emotional response to death and dying.

Nurse educators and managers should be susceptible on the importance of nurses' death anxiety in the development of nursing curriculum and policy. The role of death education is an area of further investigation, i.e. whether an appropriate palliative care educational component incorporated into the new nurse employee courses as well as in the hospital' s in-house training programs could help nurses in providing a better quality end-of-life care.

\section{References}

Bond CW. Religiosity, age, gender and death anxiety. (1998). [Online] Available: http://dunamai.com/survey/fddyq/fddy.htm.

Brockopp DY, King DB, Hamilton JE. (1991). The dying patient: A comparative study of nurse caregiver characteristics. Death Studies, 15: 245-258.

Dunn KS, Otten C, Stephens E. (2005). Nursing experience and the care of dying patients. Oncology Nursing Forum, 32(1): 97-104.

Fein Rashi. (1999). Medical Care, Medical Costs: The Search for a Health Insurance Policy. Harvard University Press, 1999.

Freud S. (1915). Thoughts for the Times on War and Death 1915. [Online] Available: http://www.freudfile.org/psychoanalysis/papers_11.html

Hopkinson J.B., Hallett C.E. \& Luker K.A. (2005). Everyday death: how do nurses cope with caring for dying people in hospital? International Journal of Nursing Studies, 42(2), 125-133.

Kübler-Ross E. (1969). On death and dying. New York, Collier Books, 1969.

Malliarou M, Sarafis P, Karathanasi K, Serafeim T, Sotiriadou K, Theodosopoulou E. (2010). Translation and validation of a DAP- R questionnaire. Themata eidikis epidimiologias kai koinonikis iatrikis. Scientific edition of Laboratory of Hygiene and Environmental Protection, Medical School, Democritus University of Thrace, Postgraduate Programme Health and Safety in Workplace, Medical School, Democritus University of Thrace, Alexandroupolis, Greece. (5); 29-38.

Mallory J. (2003). The Impact of a Palliative Care Educational Component on Attitudes toward Care of the Dying in Undergraduate Nursing Students. Journal of Professional Nursing, 19(5): 305-312.

McWhan K. (1991). Caring for dying patients in acute hospital wards: a review. Nursing Practice, 5(1), 25-8.

Neimeyer, R. A., \& Van Brunt, D. (1995). Death anxiety. In H. Wass \& R. A. Neimeyer (Eds.), Dying: Facing the facts (3rd ed.). Washington, DC: Taylor \& Francis

Neimeyer, R. A., Wittkowski, J., \& Moser, R. P. (2004). Psychological research on death attitudes: An overview and evaluation. Death Studies 28, 309-340.

Payne SA, Dean SJ, Kalus C. (1998). A comparative study of death anxiety in hospice and emergency nurses. Journal of Advanced Nursing, 28: 700-706.

Rooda LA, Clements R, Jordan ML. (1999). Nurses' Attitudes toward Death and Caring for Dying Patients. Oncology Nursing Forum, 26(10): 1683-1687.

Schulz, R., \& Aderman, D. (1978). Physician death anxiety and patient outcomes. Omega: Journal of Death and Dying, 1978-79; 9, 327-332.

Servaty HL, Krejci MJ, Hayslip JB. (1996). Relationships among death anxiety, communication apprehension with the dying, and empathy in those seeking occupations as nurses and physicians. Death Studies, 20: 149-161.

Tomer Adrian. (2000). Death Related Attitudes: conceptual dimensions, in Adrian Tomer (ed) Death Attitudes and the Older Adults: Theories, Concepts and Applications. Taylor \& Francis, Washington D.C.

Waltman N, Zimmerman L. (1992). Variations among Nurses in Behavioral Intentions toward the Dying. The Hospice Journal, 7(4): 37 - 49.

Wong T.P., Gesser G, Reker G.T. (1987). Death attitudes across the life-span: The development and validation of the Death Attitude Profile (DAP). Omega, 18: 104-124. 
Wong T.P., Peker G.T. and Gesser G. (1994). Death Attitude Profile-Revised. A multidimensional measure of attitudes toward death, in Robert Neimeyer (ed) Death Anxiety Handbook, Research, Instrumentation and Application. Taylor \& Francis, Washington D.C.

Table 1. Demographic characteristics of the sample

\begin{tabular}{|c|c|c|}
\hline Characteristics & percentage & $\mathrm{n}=150$ \\
\hline Mean age \pm SD (year) & $35.54 \pm 7.24$ & \\
\hline Mean duration of nursing \pm SD (year) & $12.1 \pm 8.07$ & \\
\hline \multicolumn{3}{|l|}{ Gender } \\
\hline Male & $18 \%$ & 27 \\
\hline Female & $82 \%$ & 123 \\
\hline \multicolumn{3}{|l|}{ Marital status: } \\
\hline Married & $58 \%$ & 87 \\
\hline Divorced & $10 \%$ & 15 \\
\hline Single & $32 \%$ & 48 \\
\hline \multicolumn{3}{|l|}{ Working role } \\
\hline Head nurse & $6 \%$ & 9 \\
\hline Clinical registered nurse & $52 \%$ & 78 \\
\hline Nurse assistant & $42 \%$ & 63 \\
\hline \multicolumn{3}{|l|}{ Education level } \\
\hline 2-year & $42 \%$ & 63 \\
\hline Technological & $42 \%$ & 63 \\
\hline University & $16 \%$ & 24 \\
\hline \multicolumn{3}{|l|}{ Having had Death education } \\
\hline Yes & $46 \%$ & 69 \\
\hline No & $54 \%$ & 81 \\
\hline \multicolumn{3}{|l|}{ Work setting } \\
\hline Inpatient & $60 \%$ & 90 \\
\hline Outpatient & $2 \%$ & 3 \\
\hline OR & $32 \%$ & 48 \\
\hline $\mathrm{ICU}$ & $2 \%$ & 3 \\
\hline ER & $4 \%$ & 6 \\
\hline \multicolumn{3}{|l|}{ Years as a nurse } \\
\hline $0-1$ & $12 \%$ & 18 \\
\hline $2-4$ & $14 \%$ & 21 \\
\hline $5-10$ & $22 \%$ & 33 \\
\hline$\ngtr 10$ & $52 \%$ & 78 \\
\hline
\end{tabular}

Table 2. Additional questions about how Greek nurses deal with death

\begin{tabular}{|l|c|}
\hline $\begin{array}{l}\text { Have you ever communicated death issues with } \\
\text { end-of-life patients }\end{array}$ & $\begin{array}{c}\text { Percentage } \\
\mathrm{n}=150\end{array}$ \\
\hline Yes & $46 \%$ \\
\hline No & $54 \%$ \\
\hline $\begin{array}{l}\text { How uncomfortable do you feel communicating } \\
\text { death issues? }\end{array}$ & \\
\hline Very much & $36 \%$ \\
\hline Not much & $60 \%$ \\
\hline Not at all & $4 \%$ \\
\hline Discuss openly death issues & \\
\hline Yes & $12 \%$ \\
\hline No & $88 \%$ \\
\hline
\end{tabular}


Table 3. Mean scores of DAP-R sub-scales

\begin{tabular}{|l|c|c|c|c|}
\hline & $\min$ & $\max$ & mean & SD \\
\hline Fear of death & 1.9 & 14.4 & 4.9 & 1.9 \\
\hline Death avoidance & 1.2 & 7.0 & 4.9 & 1.5 \\
\hline Neutral acceptance & 4.0 & 7.0 & 5.6 & 0.9 \\
\hline Approach acceptance & 1.0 & 6.0 & 4.2 & 1.2 \\
\hline Escape acceptance & 1.0 & 6.4 & 2.9 & 1.6 \\
\hline
\end{tabular}

Table 4. Cross - correlation of DAP-R sub-scales

\begin{tabular}{|l|l|c|c|c|c|}
\hline & & Death avoidance & Neutral acceptance & Approach acceptance & Escape acceptance \\
\hline Fear of death & $\mathrm{r}$ & 0.35 & -0.43 & 0.23 & 0.20 \\
\hline & $\mathrm{P}$ & $<0.001$ & $<0.001$ & 0.021 & 0.042 \\
\hline Death avoidance & $\mathrm{r}$ & & 0.03 & 0.29 & 0.07 \\
\hline & $\mathrm{P}$ & & 0.801 & 0.004 & 0.514 \\
\hline Neutral acceptance & $\mathrm{r}$ & & & 0.03 & 0.01 \\
\hline & $\mathrm{P}$ & & & 0.768 & 0.959 \\
\hline Approach acceptance & $\mathrm{r}$ & & & & 0.46 \\
\hline & $\mathrm{P}$ & & & & $<0.001$ \\
\hline
\end{tabular}

Pearson's $\mathrm{r}$

Table 5. Cross -correlation of age with DAP-R subscales

\begin{tabular}{|c|c|c|}
\hline & & Age \\
\hline Fear of death & r & 0.11 \\
\hline & $\mathrm{P}$ & 0.257 \\
\hline Death avoidance & $\mathrm{r}$ & 0.27 \\
\hline & $\mathrm{P}$ & 0.006 \\
\hline Neutral acceptance & $\mathrm{r}$ & 0.03 \\
\hline & $\mathrm{P}$ & 0.760 \\
\hline Approach acceptance & $\mathrm{r}$ & 0.07 \\
\hline & $\mathrm{P}$ & 0.513 \\
\hline Escape acceptance & $\mathrm{r}$ & -0.02 \\
\hline & $\mathrm{P}$ & 0.828 \\
\hline
\end{tabular}

Pearson's r

Table 6. Statistical significance of gender with DAP-R subscales

\begin{tabular}{|l|c|c|c|}
\hline DAP-R subscales & $\begin{array}{c}\text { Men } \\
n=27\end{array}$ & $\begin{array}{c}\text { Women } \\
n=123\end{array}$ & p-value \\
\hline Neutral acceptance & 5.31 & 5.70 & NS \\
\hline Approach acceptance & 4.88 & 4.00 & 0.004 \\
\hline Escape acceptance & 3.07 & 2.86 & NS \\
\hline Fear of death & 5.57 & 4.80 & 0.047 \\
\hline Death avoidance & 5.27 & 4.80 & 0.007 \\
\hline
\end{tabular}

Student's t-test 